\section{Dental therapy in the United Kingdom: part 3. Financial aspects of current working practices}

\author{
S. A. Williams, ${ }^{1}$ S. Bradley, ${ }^{2}$ J. H. Godson, ${ }^{3}$ J. I. Csikar ${ }^{4}$ \\ and J. S. Rowbotham ${ }^{5}$
}

VERIFIABLE CPD PAPER
IN BRIEF

- This paper presents the findings from a survey which looked at remuneration arrangements as reported by UK dental therapists.

- Many therapists were in receipt of more than one type of payment mechanism.

- Concerns were expressed that levels of clinical responsibility as therapists were not always commensurate with remuneration.

- This could influence future recruitment and retention in some circumstances.

Objectives To enquire into current remuneration arrangements among UK dental therapists and to explore the nature of any financially related concerns. Methods Part of the postal survey of therapists described in the previous paper in this series. Results The majority of therapists (63\%) often work in multiple locations and therefore may be in receipt of more than one type of payment mechanism. Two thirds of therapists are paid an hourly rate in at least one of the locations where they work; just over half are paid a fixed monthly amount and one third are self-employed. Nine percent of respondents were receiving performance-related pay, using goal setting, incentives and bonuses. A number of financiallyrelated concerns were identified. Conclusion Diverse payment systems were reported. Some aspects could present important implications for future recruitment and retention.

\section{INTRODUCTION}

Concern about cost-effectiveness of therapists is a long-standing issue. In 1984, Woolgrove and Boyles commented that therapists appear to be 'good value' as they earn less than dentists. ${ }^{1}$ It has been argued

\section{DENTAL THERAPY IN THE UNITED KINGDOM \\ 1. Development in therapists' training and role \\ 2. A survey of reported working practices \\ 3. Financial aspects of current working practices \\ 4. Teamwork - is it working for dental therapists?}

${ }^{1}$ Emeritus Professor in Oral Health Services Research, Dental Public Health, Leeds Dental Institute, Clarendon Way, Leeds, LS2 9LU; ${ }^{2}$ General Dental Practitioner/PCT Dental Adviser, Primecare Oral Health Services, Bedale Health Centre, Sussex Street, Bedale, North Yorkshire, DL8 2AH; ${ }^{3}$ Honorary Lecturer, Dental Public Health, Leeds Dental Institute/Consultant in Dental Public Health, NHS Bradford and Airedale, Douglas Mill, Bowling Old Lane, Bradford, BD5 7JR; ${ }^{4^{*}}$ Researcher, Dental Public Health, Leeds Dental Institute/Senior Public Health Manager, NHS Bradford and Airedale, Douglas Mill, Bowling Old Lane, Bradford, BD5 7JR; ${ }^{5}$ Dental Therapist/Principal Tutor, Programme of Dental Hygiene and Dental Therapy, Leeds Dental Institute, Clarendon Way, Leeds, LS2 9LU

${ }^{*}$ Correspondence to: Ms Julia Csikar

Email: j.i.csikar@leeds.ac.uk

\section{Refereed Paper}

Accepted 8 April 2009

DOI: $10.1038 /$ sj.bdj.2009.1010

${ }^{\circledR}$ British Dental Journal 2009; 207: 477-483 that the economic case for delegation rests on lower pay and status of therapists. It also assumes that salary differentials will continue to be maintained and can be justified in terms of responsibility and training. ${ }^{2}$ The role of women as therapists and men as the dentists was also seen to be part of this pay differential, ${ }^{2}$ a situation that has changed substantially since 1984 .

Hygienists have long been accepted as economically viable. McKendrick (1971) demonstrated that it was cheaper for hygienists to provide preventive measures than for a dentist to treat the resulting disease. ${ }^{3}$ In the past, evaluation of therapists' output has shown it to be comparable to that of hygienists, ${ }^{4}$ while high productivity can result from incentives and organisation. ${ }^{5-7}$ Since UK therapists do not require direct personal supervision, they may be more cost-effective than their American counterparts. ${ }^{2}$

For many years, dental therapists were restricted to working in the hospital and salaried public dental services (SDS) performing a limited range of clinical competencies. In contrast, hygienists have been able to negotiate a range of payment possibilities since they have been permitted to work across salaried and general dental practice (NHS and private) settings.

From 2002, therapists have been able to expand their clinical duties and responsibilities. Subsequently, employment opportunities widened to include general dental practice, firstly in England within personal dental services (PDS) pilots, which were established to test alternative ways of delivering dental services using local innovative contracting arrangements, and later within both NHS and private general dental practice. However, a previous report of findings from the present survey found that some therapists in general dental practice were undertaking a substantial proportion of hygiene duties within their overall remit. $^{8}$

The debate about cost-effectiveness related to team working involving dental therapists has continued. ${ }^{9-11}$ In NHS general dental practice in England and Wales, changes involving the new dental contract have required an adjustment in the mindset from fee-for-item of service (FIS) reimbursement to unit of dental activity (UDA) generation for payment. At the same time in the salaried NHS services throughout the UK, 'Agenda for change' has been introduced as a single pay system, applicable to all directly employed NHS staff (except doctors, dentists and some senior managers), creating a banding process which has led to variations even within staff groups in pay and allocated bandings.

Under the FIS payment system contract, one quarter of dentists surveyed had felt that finance was a major barrier to 
employing therapists, due to lack of NHS funds and the 'uneconomic GDS scale.' ${ }^{12}$ At that time, it was also suggested that salaries for therapists working in the FISbased NHS general dental practice setting were impracticable., ${ }^{913}$ Respondents seemed reluctant to accept that therapists would generate enough income to pay their salaries, even at the lower salary scale of the therapist. ${ }^{12}$ Even in England and Wales under the new dental contract, since NHS workloads are based on historic fee scales, it was anticipated that adding a therapist to the team would not be self-financing, 9 although it could enable a dentist to carry out more complex and well remunerated procedures either within the NHS or privately.

The aim of this study was to survey current remuneration arrangements among UK dental therapists (in October 2006) and to explore the nature of any financially related concerns.

\section{MATERIALS AND METHODS}

The 470 respondents to the previously described questionnaire survey ${ }^{8}$ who stated that they were working as a therapist, either part-time or full-time, were the subject of this analysis. These included some who would also be qualified as hygienists. The data excluded those respondents who stated that they only performed clinical duties related to dental hygiene.

The questionnaire posed four key questions regarding type(s) of employment: whether the respondents were selfemployed, paid an hourly rate, a fixed monthly amount and whether the pay was performance-related. The results were cross tabulated with other questions reported on previously, ${ }^{8}$ including the percentage of their clinical NHS time commitment, whether working in public salaried or NHS/ private dental practice settings, whether undertaking mainly hygiene duties, and the year when they gained their therapy qualification. Semi-structured and open questions afforded the opportunity for respondents to provide free text answers with a qualitative perspective from which themes related to pay were extracted in order to identify key issues.

The frequencies were described in relation to various working patterns. In order to avoid confounders, logistic regression was used to assess whether the settings

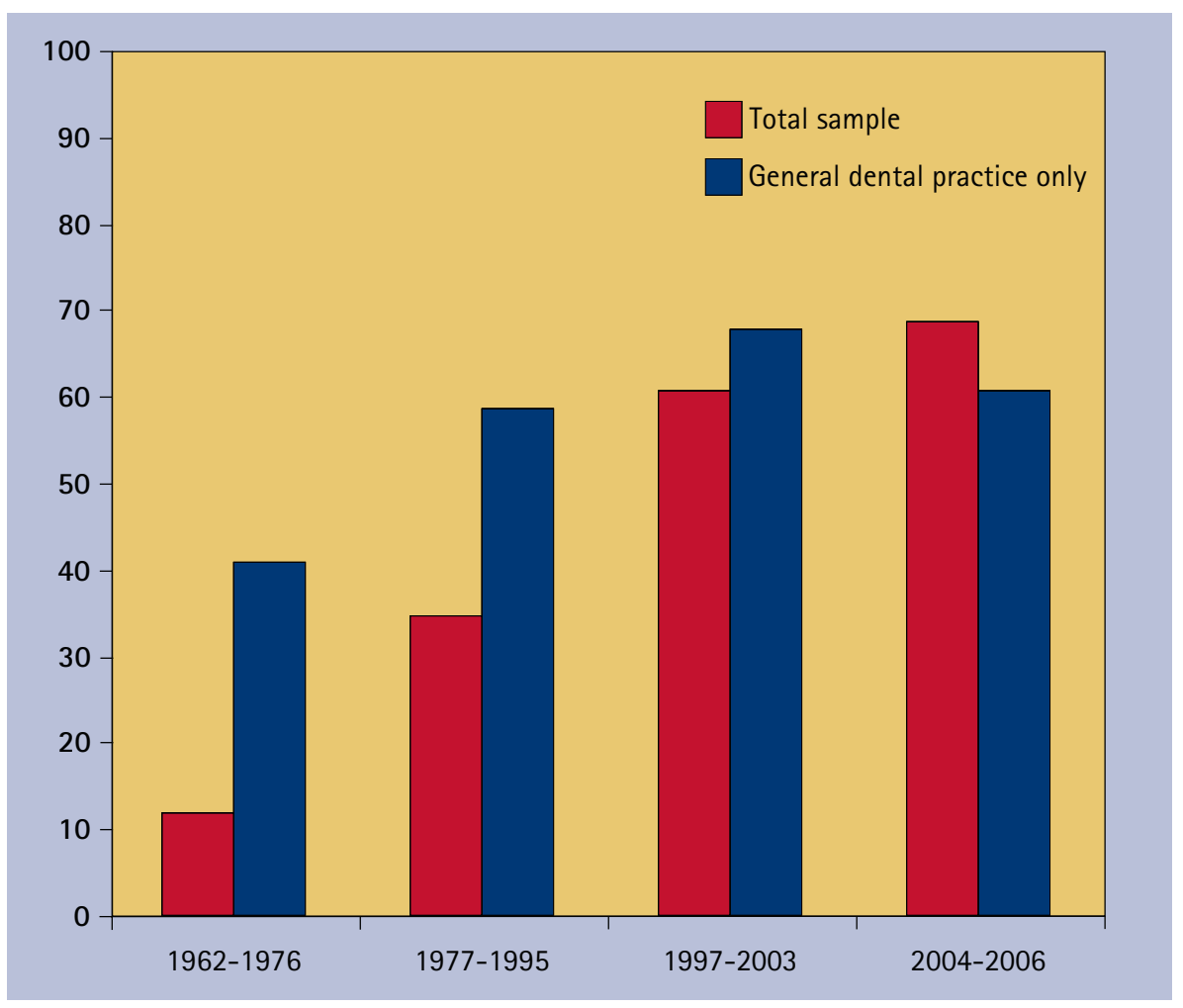

Fig. 1 Percentage of therapists stating that they were self-employed, by year of qualification as a therapist $(n=470)$

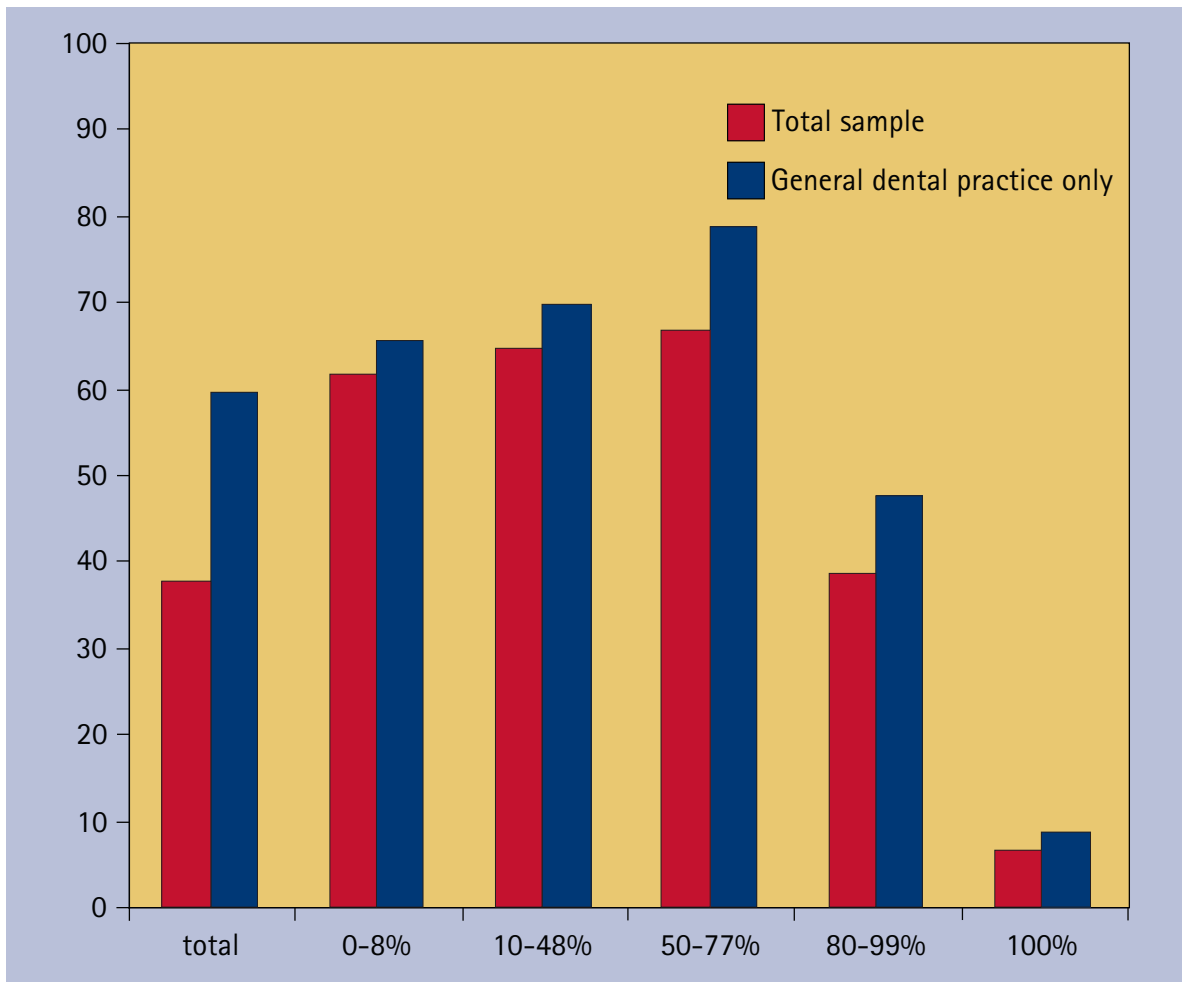

Fig. 2 Percentage of self-employed therapists, by percentage of NHS work undertaken $(n=470)$

and situations in which therapists worked, the proportion of NHS clinical time and years since qualification affected the various payment arrangements. The threshold for statistical significance adopted was the 5\% level.

\section{RESULTS}

The response rate achieved was $80.6 \%$. The majority of respondents were based in England and Wales (94\%), with 5\% from Scotland and 1\% from Northern Ireland. Among the respondents, 210 trained at 
New Cross $^{14}$ (representing a larger proportion of older therapists). Of the 470, 192 were qualified separately as a therapist and as a hygienist, while 58 had successfully completed the combined course more recently.

\section{Remuneration arrangements}

Enquiry was made regarding the different types of remuneration received. Some therapists worked in more than one type of practice or location and under varying financial arrangements. Overall, the majority (64\%) were paid an hourly rate and over half (56\%) received a fixed amount each month. Just one third (38\%) were self-employed while $8 \%$ were on performance-related pay.

The (38\%) who were either wholly or partly self-employed were more likely to:

- Have been qualified in dental therapy more recently - between 1997-2003 and 2004-2006 (64\%)

- Spend their time in mixed practice (50-77\% NHS: 67\%)

- Work in a general practice (61\%).

These variations are illustrated in Figures 1 and 2, for all therapists and for those working in general dental practice only. Logistic regression was performed with 'self-employed' as the dependent variable. The significant dichotomised predictor variables in decreasing order of significance involved 'working in private general dental practice' and 'principally undertaking hygiene duties'.

The (64\% of) therapists who were either wholly or partly paid an hourly rate were more likely to:

- Have been qualified in dental therapy more recently (between 2004-2006) (79\%)

- Spend their time in mixed practice (10-48\% NHS: 84\%)

- Work in a general practice (85\%).

Figure 3 illustrates this gradient in relation to year of qualification in more detail for all therapists and for those working in general dental practice only. Again logistic regression was calculated with 'hourly rate payment' as the dependent variable. The significant predictor variables were 'working in general dental practice' and 'performing mainly hygiene duties'.

Those therapists (56\%) who were either

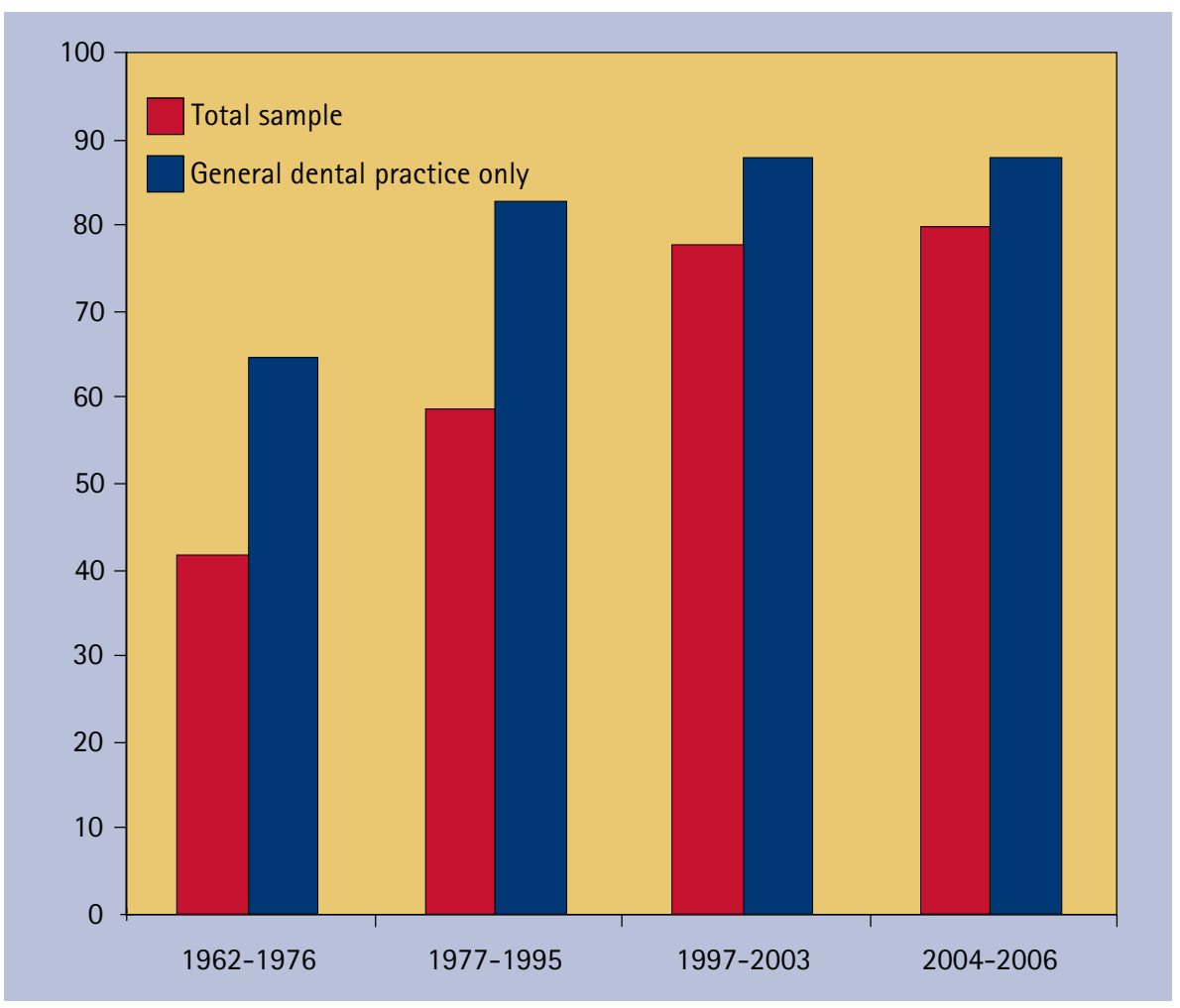

Fig. 3 Percentage of therapists stating that they were paid an hourly rate, by year of qualification $(n=470)$

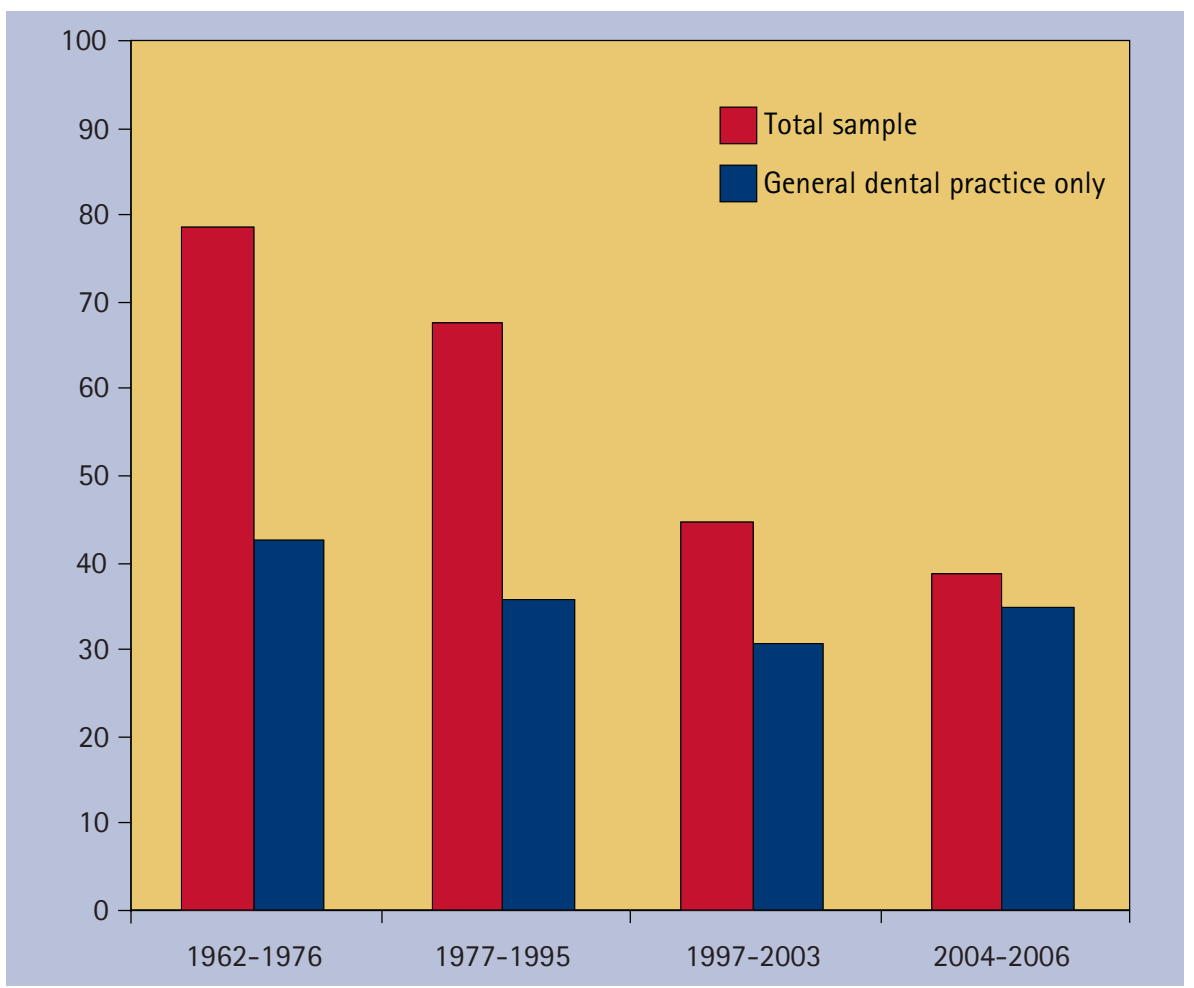

Fig. 4 Percentage of therapists stating that they were paid a fixed monthly amount, by year of qualification $(n=470)$

wholly or partly paid a fixed monthly amount were more likely to:

- Have been qualified in dental therapy the longest (between 1962-1976) (79\%)

- Work entirely in the NHS
(100\% NHS: 89\%)

- Work in the salaried service (89\%).

These trends are illustrated in Figures 4 and 5. Logistic regression with 'fixed monthly pay' as the 
dependent variable found that 'working in the salaried services', 'working substantially in the NHS' and 'having been qualified for more than 10 years' were significant predictors.

Those therapists (9\%) who were either wholly or partly on performance-related pay were more likely to:

- Have been qualified in dental therapy between 1997-2003 (14\%)

- Work in mixed practice

(10-48\% NHS: 18\%)

- Work in general practice (13\%)

Logistic regression analysis failed to establish any predictor variables for "performance-related pay'

There were 22 respondents who chose to provide additional information about their payment arrangements. Some of the responses below illustrate the range of remuneration arrangements that had been set up:

'Basic rate then $45 \%$ of anything above that I earn.'

'I get an additional 25\% of any private work I sell above my hourly rate.'

'Six monthly reviews with goals set and to be met by the next six month review.'

'If I meet my quarterly target of UDAs I receive a bonus of about $£ 170$ on top of my salary.'

'For every hour of private treatment I complete I get an extra £10 per hour (£35 rather than $£ 25$ per hour for NHS fillings). This also encourages the associate dentists to refer adults rather than just children on the NHS as they receive a fee for referring private to me and are charged when they refer NHS.'

'I must achieve a stated hourly average turnover for my private work.'

'I am paid a basic day rate. However if the percentage I receive from each patient's visit exceeds my basic day rate then I am paid the percentages.'

'I have a target figure I need to reach each month. This is not usually a problem.'

Since some therapists work in different

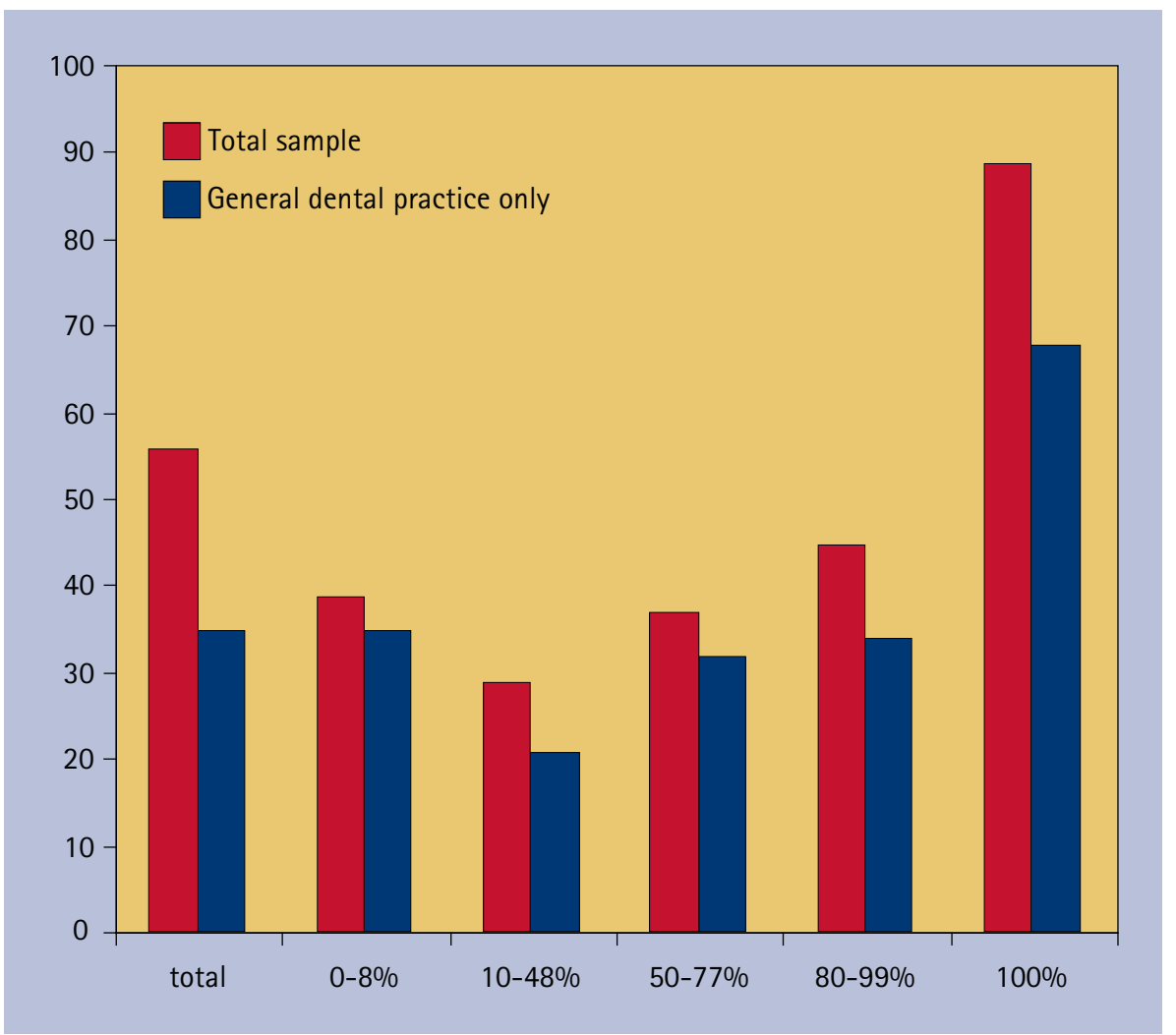

Fig. 5 Percentage of therapists paid a fixed monthly rate, by percentage of NHS work undertaken $(n=470)$

clinical settings, a few comments reflected the corresponding variation in payment methods:

'I have self-employed status/associatetype arrangement: 50/50 in one practice and an hourly rate at the other.'

'Where I work in private practice as a hygienist I am paid per patient. As a therapist, I am paid hourly.'

'I am paid $40 \%$ of fees at one private practice, but paid the hourly rate at two other NHS practices.'

The qualitative information arising from this study provided additional themes relevant to this analysis. The largest range of responses related to concerns about low pay $(n=56)$, some of which were linked to 'Agenda for change' (in the salaried services: $\mathrm{n}=19$ ) or in England and Wales to aspects of the new dental contract $(n=21)$.

\section{Concerns about low pay}

Some responses were nonspecific while others addressed particular situations, including the pay in relation to responsibilities of tutor therapists. Many respondents felt aggrieved that hygienists earn more, although they have less stress or responsibility. Yet 15 commented that hygienists can generate more income for the practice.

'I am very disappointed with my career as a therapist. The remuneration is poor for the work I do and the stress that goes with it.'

'I worked for three years as a dental therapist in general practice - payment system is very poor compared to hygienist work therefore I am not prepared to take the extra responsibility.'

'The pay is in no way related to the skills necessary to carry out the work we do. I have to work as a hygienist half my week because I get paid more even though I would rather work as a therapist full time.'

'I think most dentists don't feel having a therapist is cost-effective in general practice (especially if it's all private). Some dentists view having a hygienist as a good way of making money - no nurse, limited equipment, low overheads. Not so therapy.'

\section{Impact of 'Agenda for change': salaried services}

Many felt that their clinical training and responsibilities should result in a higher banding than that of a senior nurse, but 
this was not necessarily the case. There was a general feeling of lack of recognition. Some were appealing against their banding decisions. There was also considerable variation between different NHS employing agencies (trusts/boards).

'Agenda for change is not fair. Therapists across the country on different grades are doing the same job! Decisions of grades made by local Agenda for change personnel are not consistent.'

'Agenda for change in the NHS has caused a lot of unrest. Nurses can now be on same pay bands as therapists which is causing therapists to leave community and go and do hygiene in practice. Salaries in community for therapists are still very poor considering responsibilities that therapists have - giving ID blocks etc.'

For some working in the salaried services, professional fulfilment in completing treatment for a patient was judged as more rewarding than the salary:

'Pay in the community is an insult. I can't see many new therapists working for $£ 12.50$ an hour when $£ 30$ could be made in general practice. I still after 35 years get a buzz from what I do and feel I make a difference, the only reason I am still working for such poor pay.'

\section{Impact of the new dental contract in general dental practice (England and Wales)}

For some, the new contract had engendered a sense of insecurity as there were fewer referrals. Others felt that they were expected to perform more hygienist-type duties than they would have wished.

'There seems to be constant instability since April 2006 as to whether therapists are viable in general practice.'

'Since the new dental contract, UDAs are being measured ... less work is being referred. Associate dentists under the new scheme don't refer any more as they don't get paid for US to do the work! Only the principle dentist refers work now ... I have to look for extra work at other practices and I am still looking.'

'The reality is that dentists cannot see any financial gain [using therapists with the UDA system].'
Some responses illustrated how the payment system has been interpreted in relation to therapists making referral to them less attractive within general dental practice:

'Jobs in general practice are few and far between. Post-UDAs, therapists are not needed in NHS as only dentists can get UDAs.'

'Practices in my area do not have any spare UDAs to pass on to dental therapists and there is no more funding available from local PCTs.'

One respondent was advised that working in the salaried service (for £12 per hour) was more lucrative than staying in general dental practice. For some, the private sector beckoned. Others were frustrated by payment systems that depended on 'results' when they were referred only difficult cases.

'I fear that if I am to find secure work I will need to move into the private sector. Considering the fact that the NHS funded my training it seems ridiculous that they are now making it pretty impossible for us to work within the NHS.'

'I declined the PDS post as salary was $£ 10 K$ short of hygienist salary. Going into private practice with children which I am happy with and enjoy doing.'

'Currently [in GDS] I am referred the "impossible to treat" patients, therefore I don't get paid. The dentist will not pay me an hourly rate.'

\section{Other observations}

A lack of standardisation between practices was a cause for concern:

'Some dentists see therapists as money making machines. From my own experience, if my principal sees one gap in my working day he starts to consider reducing my hours.'

'Dentists are very sceptical and unwilling to pay acceptable wages.'

'Salaries differ greatly between one practice and another: they should be standardised.'

Fifteen therapists felt that the inequity between themselves and other dental care professionals (DCPs) should be recognised in terms of their higher level of training, clinical responsibilities and their pay needed to be addressed. Eight referred to the higher stress levels.

'The salary scale in general practice must recognise the extra skills the therapist has over the hygienist and payment should reflect that.'

'In view of our extended duties carried out in dental therapy, I feel a pay review is necessary because of the added responsibility and work carried out and for the difficulty of type of patients we treat. Very few GDPs seem to treat children now and refer to us as untreatable, but expect us to carry out treatment. Perhaps things will change with more therapists in general dental practice.'

\section{DISCUSSION}

The high response rate obtained implies that many of these findings can be generalised. The majority of responses came from England and Wales, some referring to the specific contracting arrangements prevalent there. However, many responses are equally valid throughout the UK, including those related to the impact of 'Agenda for change'. Some respondents opted to provide additional textual information, which underlines the value of following up aspects of this study with an appropriately designed in-depth qualitative assessment.

The results of this study confirm that those therapists who qualified in earlier years were more likely to work in the salaried services and receive fixed monthly payments. Being self-employed or paid an hourly rate was more often associated with working in general dental practice, including seeing private patients and performing more hygiene duties. Performance-related pay involved only $9 \%$ of respondents, who were most likely to work in a mixed private/NHS practice setting.

Out of the 470 responders, 22 chose to comment regarding payment mechanisms, the majority expressing dissatisfaction. In general dental practice, this seems to focus on being used for hygienist duties, where earning potential may be higher, or for treating difficult children, where earning potential is low. As therapists become more highly trained, better paid 
and require surgery space, equipment and (fully qualified) nursing assistance, unit costs increase. ${ }^{9}$ Employing a therapist depends on practice productivity and, ultimately, cost. While many therapists feel their skills are not being fully utilised, it must be remembered that providing high quality patient care and economic viability is a delicate balancing act. The skills of the team must be used in such a way that their capabilities are maximised. Treatment which is outside the competence of a therapist ${ }^{15}$ must be carried out by a dentist, but to refer as much work as possible to a therapist would free up more of the dentist's time for more complex or private treatment. This study has provided some useful examples of goal setting, incentives and bonuses to encourage productivity among therapists.

It has long been recognised that the therapeutic role of therapists is not directly costed. ${ }^{4}$ Longer term health gain must be taken into account. ${ }^{16}$ Building up a preventive practice ethos may be seen to add 'value', but under the present systems, any financial gain is more uncertain. ${ }^{9}$ However, if preventive tasks formed part of the dentist's rather than the therapist's workload, the profit margin would be even more questionable.

It has previously been noted that General Dental Practitioners (GDPs) would need to plan payments carefully as the introduction of the new dental contract might make therapists' employment financially non-viable. ${ }^{6}$ When principal dentists were consulted in Wales, 29\% thought that hygienist/therapists should be self-employed, $22 \%$ that they should be employed while $33 \%$ stated no preference. There was concern that expected salaries might be disproportionate to therapists' earning and productivity capacity, and that at $£ 30$ per hour they would not prove cost-effective (having to gross $£ 50-£ 60$ per hour). Overall, it was suggested that practice profitability could be improved by employing hygienist/therapists on an hourly rate once UDAs were introduced. ${ }^{6}$

In England and Wales, there seems to be some professional misunderstanding about the earning of UDAs. It is correct to say that the UDA earned can only be attributed to a dentist with a performer number. However, that treatment can be completed by a therapist without the need for the dentist to see the patient after the examination. The majority of patients are provided with treatment in Band 1 or in Band $2,{ }^{17}$ which is normally within the scope of a therapist. It may be argued that the therapist would not earn extra UDAs for the practice in these circumstances, but this only looks at one side of the equation. If the therapist were to complete as much treatment as possible, it would reduce the appointment time needed with the dentist to complete treatment and the productivity of the dentist in the time saved must be accounted for in assessing the viability of the therapist.

Contracts for NHS services are normally agreed at practice level between the provider and the contracting organisation. The staffing required to deliver the contract targets within the contract value is a practice decision. A dentist may wish to develop more private work and could pass some of their contract value to a therapist or perhaps replace a departing dentist with a therapist.

There are discussions within the profession about how dental contracts will be monitored in the future and in response to the Health Select Committee report on dental services (July 2008), ${ }^{18}$ the Department of Health commissioned an independent review. ${ }^{19}$ The Steele Review has emphasised the need for transition from dental activity to oral health using care pathways, ${ }^{19}$ while finding ways "to support dentists to make best and most cost-effective use of the available dental workforce'. Linking commissioning to the best use of skill mix is also a key component of the Report of the BDAs Independent Local Commissioning Working Group. ${ }^{20}$ In addition, within the Government response it was announced that a new access indicator will be developed in consultation with stakeholders. At present, the feeling is that there will be less emphasis on UDAs as the sole measure and more interest in a broader range of indicators, ${ }^{19}$ including preventive advice such as dietary control and oral hygiene regimes, application of topical fluorides, the prescription of high fluoride content toothpastes and smoking cessation advice. Other indicators of a successful practice may be information on waiting times, availability of appointments for urgent care, new patient acceptance and patient satisfaction surveys. The therapist in practice can contribute significantly to a number of these indicators and will become a valued member of the team.

Across the UK within the salaried services, 'Agenda for change' has created a substantial degree of dissent in terms of the level of the award in relation to other dental healthcare workers. Nevertheless, there are benefits to working in a large organisation, including support facilities, in-service training and in this case, the opportunity to focus on special groups of patients. Since the salaried services are more likely to employ older therapists who will be facing retirement, recruitment could present a major challenge in this area in the near future.

It has been argued that the cost-effectiveness of DCPs depends on an unmet demand for dental services ${ }^{16}$ and areas of high need and low access. ${ }^{12}$ Ultimately, it has been suggested that it would be cheaper to allow therapists to work independently, with referral from therapists to a dentist ${ }^{2,13}$ as in some skill mix arrangements in medicine. Not having the dentist see and assess every patient would help DCPs to be costeffective if they can develop the competencies to carry out the basic examination and formulate a treatment plan as practised in New Zealand. ${ }^{14}$ Alternative models might also include dental centres established in areas of need where therapists, paid from a monetary allocation from the NHS (rather than from the dentist), could receive referrals from GDPs. ${ }^{13}$

In conclusion, this study has confirmed that two thirds of therapists are paid an hourly rate in at least one of the locations where they work. Similarly, just over half are paid a fixed monthly amount and one third are self-employed. A number of financially-related concerns were identified, some of which may have implications for future recruitment and retention.

\section{This project was funded by NHS R\&D in Primary} Dental Care.

1. Woolgrove J, Boyles J. Operating dental auxiliaries in the United Kingdom - a review. Community Dent Health 1984; 1: 93-99.

2. Scarrott D M. The economic case for delegation in dentistry. Br Dent J 1973; 134: 23-24.

3. McKendrick, A. The economics of caries prevention by dental hygienists. Public Health 1971; 85: 219-227.

4. Holt R D, Murray J J. An evaluation of the role of New Cross dental auxiliaries and of their clinical contribution to the community dental services. BrDent J 1980; 149: 259-262.

5. Jones D E, Gibbons D E, Doughty J F. The worth of a therapist. Br Dent J 1981; 151: 127-128.

6. Jones G, Devalia R, Hunter L. Attitudes of general dental practitioners in Wales towards employing 
dental hygienist-therapists. Br Dent J 2007; 203: E19.

7. Gibbons D, Corrigan M, Newton J T. The working practices and job satisfaction of dental therapists: findings of a national survey. Br Dent J 2000; 189: 435-438.

8. Godson J H, Williams S A, Csikar J I, Bradley S, Rowbotham J S. Dental therapy in the United Kingdom: part 2. A survey of reported working practices. Br Dent J 2009; 207: 417-423.

9. Harris R, Burnside G. The role of dental therapists working in four personal dental service pilots: type of patients seen, work undertaken and cost-effectiveness within the context of the dental practice. Br Dent J 2004; 197: 491-496.

10. Ward P. The changing skill mix - experiences on the introduction of the dental therapist into general dental practice. Br Dent J 2006; 200: 193-197.

11. Goodwin N, Morris A J M, Hill K B et al. National evaluation of personal dental service (PDS) pilots: main findings and policy implications. Br Dent J 2003; 195: 640-643.

12. Gallagher J L, Wright D A. General dental practitioners' knowledge of and attitude towards the employment of dental therapists in general practice. $\mathrm{Br}$ Dent J 2002; 194: 37-41.

13. Ross M K, Ibbetson R J, Turner S. The acceptability of dually qualified dental hygienist-therapists to general dental practitioners in South-East Scotland. Br Dent J 2007; 202: E8.

14. Rowbotham J S, Godson J H, Williams S A, Csikar J I, Bradley S. Dental therapy in the United Kingdom: part 1. Developments in therapists' training and role. Br Dent J 2009; 207: 355-359.

15. General Dental Council. Scope of practice consultation [online]. London: GDC, 2008. www.gdc-uk.org.

16. Harris R V, Haycox A. The role of team dentistry in improving access to dental care in the UK. Br Dent J 2001; 190: 353-356

17. The Information Centre. NHS dental statistics for England. London: The Information Centre, 2007.

18. Department of Health. Further government response to the Health Select Committee report on dental services. London: Department of Health, 2009.

19. Steele J. NHS dental services in England. London: Department of Health, 2009

20. Drinkwater C. Local commissioning: opportunity or threat? London: BDA, 2009 